\title{
Prevalence of Congenital Heart Defects in Newborns in Germany: Results of the First Registration Year of the PAN Study (July 2006 to June 2007)
}

\section{Prävalenz angeborener Herzfehler bei Neugeborenen in Deutschland: Ergebnisse des ersten Geburtsjahrganges (Juli 2006 bis Juni 2007)}

\author{
Authors \\ A. Lindinger ${ }^{1}$, G. Schwedler ${ }^{2}$, H.-W. Hense \\ For the participants of the PAN Study* \\ Affiliations \\ Clinic of Paediatric Cardiology, University Hospital, Homburg/Saar, Germany \\ Epidemiology Unit, Competence Network for Congenital Heart Defects and German Heart Center Berlin, Germany \\ Clinical Epidemiology Section, Institute of Epidemiology and Social Medicine, University of Muenster, Germany
}

\section{Key words \\ - congenital heart defects \\ - prevalence \\ - newborns \\ - population-based study \\ - Competence Network for \\ Congenital Heart Defects}

\section{Schlüsselwörter \\ - angeborene Herzfehler \\ - Prävalenz \\ - Neugeborene \\ - bevölkerungsbezogene Studie \\ - Kompetenznetz Angeborene Herzfehler}

Bibliography

DOI http://dx.doi.org/ 10.1055/s-0030-1254155

Published online:

July 21, 2010

Klin Padiatr 2010; 222: 321-326

(c) Georg Thieme Verlag KG

Stuttgart - New York

ISSN 0300-8630

\section{Correspondence}

\section{Prof. Dr. Angelika Lindinger}

Klinik für Pädiatrische

Kardiologie

Universitätsklinikum des

Saarlandes

D-66421 Homburg/Saar

Tel.: +49/6841/16 28306

Fax: $+49 / 6841 / 1628455$

angelika.lindinger@uks.eu

\section{Abstract}

$\nabla$

Objective: To investigate the current prevalence of congenital heart defects (CHD) in live births in Germany and to assess its relation to demographic and gestational parameters.

Design: Nation-wide study (PAN: Praevalenz angeborener Herzfehler bei Neugeborenen) with passive registration of infants born between $1^{\text {st }}$ July 2006 and $30^{\text {th }}$ June 2007 in Germany diagnosed with CHD.

Results: Data were provided by 260 participating institutions. 7245 infants with CHD were registered to give a total $\mathrm{CHD}$ prevalence of $1.08 \%$. The most common lesions were: ventricular septal defect (all types) (48.9\%), atrial septal defect $(17.0 \%)$, valvular pulmonary stenosis (6.1\%), persistent arterial duct (4.3\%) and aortic coarctation $(3.6 \%)$. The most common cyanotic lesions were tetralogy of Fallot $(2.5 \%)$ and complete transposition of the great arteries (2.2\%). A single ventricle (all types) was identified in $2.8 \%$, half of them being a hypoplastic left heart syndrome. Female gender was more common among mild CHD (57.3\%) while there was a striking predominance of male infants among severe lesions (58.4\%). Prematurity (18.7\% vs. $9.1 \%)$, a birth weight below $2500 \mathrm{~g}$ ( $17.5 \%$ vs. $6.8 \%)$ and multiple births $(6.2 \%$ vs. $3.3 \%)$ were more frequent in infants with CHD than in all live births. More than $80 \%$ of the CHD diagnoses were made within three months after birth.

Conclusions: The PAN study recorded an overall CHD prevalence of $1.08 \%$ in Germany. The proportion of mild CHD may indicate a high diagnostic level, the prevalence of severe lesions is concordant with ranges reported by others. CHD is associated with prematurity, low birth weight and multiple births.

*listed online in the "Supporting Information"

\section{Zusammenfassung \\ $\nabla$}

Zielsetzung: Ziel der Arbeit war es, die gegenwärtige Prävalenz angeborener Herzfehler (AHF) bei Lebendgeborenen in Deutschland zu bestimmen sowie den Zusammenhang mit demografischen und Geburtsparametern zu ermitteln.

Design: Bundesweite Studie (PAN: Prävalenz angeborener Herzfehler bei Neugeborenen) mit passiver Registrierung aller Kinder, die zwischen dem 1. Juli 2006 und dem 30. Juni 2007 in Deutschland mit einem AHF geboren wurden. Ergebnisse: Von 260 kooperierenden Einrichtungen wurden 7245 Kinder mit AHF registriert; dies ergibt eine AHF-Gesamtprävalenz von $1,08 \%$. Häufigste Fehlbildungen waren: Ventrikelseptumdefekt (alle Formen) (48,9\%), Vorhofseptumdefekt (17,0\%), valvuläre Pulmonalstenose $(6,1 \%)$, persistierender Ductus arteriosus $(4,3 \%)$ und Aortenisthmusstenose (3,6\%). Die häufigsten zyanotischen Herzfehler waren Fallot'sche Tetralogie (2,5\%) und komplette Transposition der großen Arterien (2,2\%). Ein univentrikuläres Herz bestand bei 2,8\% der Patienten, davon hatten $50 \%$ ein hypoplastisches Linksherzsyndrom. Bei einfachen AHF überwog das weibliche (57,3\%), bei schweren Herzfehlern das männliche Geschlecht (58,4\%). Frühgeburtlichkeit (18,7\% zu 9,1\%), ein Geburtsgewicht unter 2500g (17,5\% zu 6,8\%) und Mehrlingsgeburten (6,2\% zu 3,3\%) waren bei Kindern mit AHF häufiger als im Bundesdurchschnitt. Mehr als 80\% der AHF-Diagnosen wurden innerhalb der ersten 3 Lebensmonate gestellt.

Schlussfolgerung: In der PAN-Studie wurde eine AHF-Gesamtprävalenz in Deutschland von $1,08 \%$ ermittelt. Der hohe Anteil leichter Herzfehler deutet auf ein hohes diagnostisches $\mathrm{Ni}$ veau hin. Die Prävalenz schwerer Herzfehler ist in Übereinstimmung mit Daten anderer Länder. AHF sind assoziiert mit Frühgeburtlichkeit, geringem Geburtsgewicht und Mehrlingsgeburten. 


\section{Background \\ $\nabla$}

Congenital heart defects are the most common single organ malformations in humans. The estimates of prevalences published during the last 3-4 decades ranged from 4-5 CHD/1000 live births in the earlier studies up to $12-14 / 1000$ live births in the more recent ones $[3,6,7,9,14,17,21]$. Higher prevalences were usually reported by echocardiography screening studies in newborn nurseries or by registries covering childhood and adolescence $[13,18]$. Hoffman and Kaplan [9] addressed the reasons for the variation in CHD prevalence rates in a meta-analysis of 62 publications. They pointed out that studies of very large populations tend to give sufficiently large numbers of live births at the expense of an adequate detection rate. On the other hand, intensive studies in a restricted region virtually disclose all CHD, but they are usually not feasible for very large populations. The prevalence of $\mathrm{CHD}$, and in particular the proportions of single lesions, depend essentially on the detection rates of mild defects $[5,9,17,21]$, and any assessment of CHD prevalence must take into account not only the age of the patients but, in particular, the ways in which they were entered into the study.

Population-wide data on current CHD prevalence are scarce and a recent review critically noted that only crude calculations and estimates were available for Germany [10]. The PAN ( $\underline{\text { Praevalenz }}$ angeborener Herzfehler bei Neugeborenen) study is making efforts to remedy the lack of research in this field. It is a nationwide epidemiological registry within the German Competence Network for Congenital Heart Defects, which is funded by the German Federal Ministry of Education and Research and involves hospitals, cardiac centers and practicing physicians in an interdisciplinary research structure.

This report summarizes the results of the first registration year of the PAN study. Data are presented for the whole group of cardiovascular defects as well as for relevant subgroups. We further provide information on the association of demographic and selected gestational data with CHD and compare these findings to those provided by official data for all live births in Germany.

\section{Material and methods}

$\nabla$

The PAN study is a nationwide investigation in Germany with the aim of a prospective registration of all congenital cardiovascular malformations diagnosed among live births during the first year of life. It is based on the resident population of more than 80 million people presently living within the territory of the Federal Republic of Germany. This report is on the first year of registration which includes the data for infants with CHD born between $1^{\text {st }}$ July 2006 and 30 $30^{\text {th }}$ June 2007. There were 673282 live births in Germany during this period.

The study was approved by the ethics committee of the Charité, Berlin. The data protection officers of all Federal States of Germany agreed with the data sampling procedures. Signed informed consent was obtained from parents/legal guardians for data acquisition and handling.

\section{Data acquisition}

All German paediatric cardiologists and paediatricians with cardiologic expertise working in specialized heart centers, children's hospitals and outpatient clinics were addressed to contribute to the PAN study data base. Finally, 34 out of 35 departments of paediatric cardiology in university units (97\%), 154 out of 192 children's hospitals (80\%) and 72 out of 111 outpatient departments (65\%) contributed patients to the study base.

Data of all patients were submitted in electronic form into a central database by a remote data entry system. All data were monitored for plausibility and correctness. To reduce underreporting and to optimize participation, a routine monthly reminder was sent to all institutions. In cases with loss of contact or non-compliance, an anonymous registration was offered.

\section{Data sets}

The patient data consisted of sets of personal and medical parameters. The Identification Data set was used to create a unique patient identifier (PID), applying encryption methods developed by the Telematics Platform for Medical Research Networks [19]. The use of PIDs permits linkage of different records by stochastic methods, which ensure low rates of misclassification and comply with German data protection requirements. Patient's data were stored in the PAN data base exclusively by their PID.

The Medical Data set consisted of demographic data, birth data, and medical data. In case of missing consent, only infant's sex, month and year of birth and diagnosis of CHD were registered anonymously.

The first place of residence of the newborn after birth had to be in Germany.

\section{Diagnosis of CHD}

Registration of cases was based on a passive patient collection with diagnosis assessment on clinical signs rather than on active screening for CHD. Diagnostic procedures included echocardiography, cardiac catheterization, surgery or autopsy.

All congenital malformations of the heart and the thoracic vessels were recorded with the following exclusion criteria:

- persistent arterial duct in a preterm infant until four weeks after calculated birth date and in a full-term infant until four weeks after birth;

- physiological branch stenosis of the right or left pulmonary artery;

- isolated patent foramen ovale;

- isolated persistent left superior vena cava;

- isolated bicuspid aortic valve;

- isolated dextrocardia;

- cardiac tumours;

- cardiomyopathies;

- cardiac arrhythmias.

Cardiac and extracardiac lesions were recorded in accordance with the Code of the Association for European Paediatric Cardiology (EPC code) [1]. Combined cardiac defects were arranged in a one-dimensional approach with the leading malformation being either the main anatomical defect or the defect which would require the earliest intervention (for example, double inlet ventricle with coarctation of aorta was coded double inlet ventricle as the major cardiovascular malformation, while coarctation or interrupted aortic arch with ventricular septal defect was coded as coarctation of the aorta or interrupted aortic arch as the main lesion). The severity of the CHD was classified as 'mild', 'moderate' or 'severe' (see footnote $\bullet$ Table 1 ).

\section{Statistical analyses}

Analyses were exclusively descriptive and the observed prevalences are reported. Tests of statistical significance are not provided as there was no prior study hypothesis to be tested. Analyses were performed with SPSS statistical software (version 17.0). 


\begin{tabular}{lccrrrr} 
& \multicolumn{2}{c}{ Total } & \multicolumn{2}{c}{ Complete data set } & \multicolumn{2}{c}{ Anonymous data set } \\
& $\mathbf{n}$ & $\%$ & $\mathbf{n}$ & $\%$ & \multicolumn{1}{c}{$\mathbf{n}$} & $\%$ \\
registered cases with CHD & 7245 & $(100)$ & 5251 & $(72.5)$ & 1994 & $(27.5)$ \\
male & 3379 & $(46.7)$ & 2474 & $(47.1)$ & 905 & $(45.4)$ \\
female & 3860 & $(53.3)$ & 2777 & $(52.9)$ & 1083 & $(54.3)$ \\
not specified & 6 & $(0.08)$ & 0 & & 6 & $(0.3)$ \\
CHD-severity*: & & & & & & \\
mild CHD & 4372 & $(60.3)$ & 3166 & $(60.3)$ & 1206 & $(60.5)$ \\
moderate CHD & 1988 & $(27.4)$ & 1440 & $(27.4)$ & 548 & $(27.5)$ \\
severe CHD & 866 & $(12.0)$ & 634 & $(12.1)$ & 232 & $(11.6)$ \\
no classification & 19 & $(0.3)$ & 11 & $(0.2)$ & 8 & $(0.4)$
\end{tabular}

* mild CHD include: VSD (small or muscular), ASD (all forms), PDA, PS, other lesions; moderate CHD include: VSD (others than small or muscular), AVSD, AS, CoA, PAPVC, other lesions; severe CHD include: UVH (all types), ToF, PA/VSD, PA/IVS, DORV, D-TGA, L-TGA, TAC, IAA, TAPVC, Ebstein's anomaly, other lesions

For abbrevations see footnote of $\bigcirc$ Table 2

\section{Results}

A total of 7245 live births with CHD were registered within the birth period from $1^{\text {st }}$ July 2006 to $30^{\text {th }}$ June 2007. Departments of paediatric cardiology in university hospitals contributed $38 \%$, children's hospitals with cardiologic care $36 \%$ and outpatients departments $26 \%$ of all cases. The number of patients included by these three institutional categories ranged from 6 to 260, 1 to 145 and 1 to 157 with a median of 70,11 and 18 , respectively. A complete data set was obtained for 5251 (72.5\%) of the patients and an anonymous data set for 1994 (27.5\%). Patients with complete and anonymous data did not markedly differ regarding sex or CHD severity ( $\bullet$ Table $\mathbf{1}$ ).

Based on the official number of live births in Germany during the study period, the total prevalence of CHD was calculated as 107.6 per 10000 live births. Among all infants with CHD, $60.3 \%$ had a mild, $27.4 \%$ a moderate and $12.0 \%$ a severe cardiovascular defect; the proportions among full term infants were $59.2 \%$, $27.9 \%$ and $12.7 \%$, respectively. The most common lesion were: ventricular septal defect (48.9\%), about two third of them being small or muscular defects, atrial septal defect (17.0\%), valvular pulmonary stenosis $(6.1 \%)$, persistent arterial duct $(4.3 \%)$ and aortic coarctation (3.6\%). The most common cyanotic lesions were tetralogy of Fallot (2.5\%) and complete transposition of the great arteries (2.2\%). A single ventricle (all types) was identified in $2.8 \%$, half of them being a hypoplastic left heart syndrome. While female infants were clearly more common in mild defects, there was a striking predominance of males with severe lesions (० Table 2).

Associated genetic anomalies were reported in $5.3 \%$ and extracardiac organ malformations in $2.3 \%$ of the patients.

As depicted in Table 3 the proportion of a gestational age of less than 37 weeks was substantially higher in newborns with CHD compared with all live births in Germany (18.7\% vs. 9.1\%). Similarly, a birth weight below $2500 \mathrm{~g}$ was more common in patients with CHD than in the average newborn (17.5\% vs.6.8\%). The rate of multiple births was nearly doubled in patients with CHD compared to all live births (6.2\% vs. $3.3 \%)$.

According to parents' self reports, a prenatal diagnosis of CHD by echocardiography was made in $12.1 \%$ of all CHD cases ( $\bullet$ Fig. 1 ). The prenatal detection rates were strongly affected by the type of defect. They were highest for univentricular hearts (68.4\%) and Ebstein's anomaly (59.1\%).

Postnatal diagnoses were made in $52.6 \%$ of the patients within the first month of life and in $82.1 \%$ within the first three months.
The time of diagnostic ascertainment varied by the type of defect, severe CHD lesions were usually detected earlier than the mild ones ( $\bullet$ Fig. 2).

\section{Discussion}

$\nabla$

The PAN register covers all of Germany with more than 670000 live births per year. The observed prevalence of CHD between July 2006 and June 2007 was 1.08 per 100 live births.

The PAN study involved nearly all institutions in Germany with a sizable CHD case load. All university departments treating in particular the moderate and severe CHD patients, participated in the PAN study with the exception of one department. Only a minority of children's hospitals and outpatient clinics refrained from active participation, mostly due to care of very low numbers or of a complete lack of patients with CHD. Internal quality checks were applied to avoid underreporting as well as multiple reporting of identical cases. Using automated PID checks in the remote data entry system and cross-checking of anonymous reports with complete records for variable identity, we could rule out duplicate registrations in at least $97.5 \%$ of severe and over 95\% of moderate CHD cases. Based on design, conduct, participation, performance and quality control, there is evidence that the PAN study enrolled more than $90 \%$ of the CHD patients born during the study period, and that the prevalences reported here are representative for Germany.

The proportion of mild cardiac lesions was comparatively high in the PAN study, indicating a high sensitivity of identifying minor lesions early in life despite being a nation-wide investigation without active screening modalities. These data are in line with other studies that noticed a significant increase in the prevalence of mild CHD, in particular of ventricular septal defects, and attributed this fact mainly to changes in the diagnostic facilities $[4,21]$. Likewise, severe cardiac malformations accounted for $12.0 \%$ of all cardiac defects in the PAN study, a finding that again is within the range of previous reports $[9,21]$. We are unable to present a prevalence trend over time for severe cardiac defects but it should be noted that prenatal detection of the lesion and consecutive intervention may have influenced the prevalence, resulting in a decrease of severe defects $[8,15]$.

The overall male/female ratio was 0.88 in the PAN study, compared to a ratio of 1.05 for all live births in the general population during this study period. It is noteworthy that this ratio was 1.41 for infants with severe cardiac lesions. This result closely 
Table 2 Prevalence of categories of CHD severity and of single cardiac lesions. Numbers of cases, proportion of total numbers, sex ratio and prevalence. The single lesions are arranged in decreasing frequency.

\begin{tabular}{|c|c|c|c|c|}
\hline \multirow[t]{2}{*}{ Cardiac Malformation } & \multicolumn{2}{|c|}{ Cases } & \multirow[t]{2}{*}{ Ratio male/female } & \multirow[t]{2}{*}{ Prevalence per 10000 live births } \\
\hline & $\mathbf{n}$ & (\%) & & \\
\hline total & 7245 & & 0.88 & 107.6 \\
\hline \multicolumn{5}{|l|}{ CHD severity* } \\
\hline mild CHD & 4372 & $(60.3)$ & 0.75 & 64.9 \\
\hline moderate CHD & 1988 & $(27.4)$ & 1.01 & 29.5 \\
\hline severe CHD & 866 & $(12.0)$ & 1.41 & 12.9 \\
\hline no classification & 19 & $(0.3)$ & 0.73 & 0.3 \\
\hline \multicolumn{5}{|l|}{ single CHD entities } \\
\hline VSD (all) & 3545 & $(48.9)$ & 0.78 & 52.7 \\
\hline - VSD small or muscular & 2260 & (31.2) & 0.75 & 33.6 \\
\hline - VSD all others & 1285 & $(17.7)$ & 0.83 & 19.1 \\
\hline ASD (all forms) & 1235 & $(17.0)$ & 0.70 & 18.3 \\
\hline$-A S D \|$ & 1219 & (16.8) & 0.69 & 18.1 \\
\hline - ASD all others & 16 & $(0.2)$ & 1.00 & 0.2 \\
\hline PS & 443 & $(6.1)$ & 0.74 & 6.6 \\
\hline PDA & 310 & (4.3) & 0.93 & 4.6 \\
\hline $\mathrm{COA}$ & 264 & (3.6) & 1.51 & 3.9 \\
\hline UVH (all types) & 202 & (2.8) & 1.56 & 3.0 \\
\hline$-H L H S$ & 101 & (1.4) & 1.53 & 1.5 \\
\hline AVSD & 183 & (2.5) & 1.08 & 2.7 \\
\hline ToF & 179 & (2.5) & 1.42 & 2.7 \\
\hline AS & 161 & $(2.2)$ & 2.83 & 2.4 \\
\hline D-TGA & 156 & $(2.2)$ & 2.90 & 2.3 \\
\hline DORV & 76 & $(1.0)$ & 0.90 & 1.1 \\
\hline PA/VSD & 44 & $(0.6)$ & 1.20 & 0.7 \\
\hline TAPVC & 43 & (0.6) & 1.15 & 0.6 \\
\hline TAC & 33 & $(0.5)$ & 1.06 & 0.5 \\
\hline Ebstein's anomaly & 27 & $(0.4)$ & 0.93 & 0.4 \\
\hline PAPVC & 26 & (0.4) & 1.00 & 0.4 \\
\hline L-TGA & 25 & $(0.3)$ & 0.92 & 0.4 \\
\hline IAA & 22 & $(0.3)$ & 0.69 & 0.3 \\
\hline $\mathrm{PA} / \mathrm{IVS}$ & 21 & $(0.3)$ & 1.10 & 0.3 \\
\hline AVSD partial & 18 & $(0.2)$ & 1.57 & 0.3 \\
\hline misc., specific lesions & 223 & (3.1) & 0.78 & 3.3 \\
\hline misc., not specified & 9 & $(0.1)$ & 0.50 & 0.1 \\
\hline
\end{tabular}

agrees with a ratio of 1.45 reported by Pradat et al. in their study based on registries of three countries [17]. Similarly, the particularly high predominance of males observed in complete transposition of the great arteries ( $\mathrm{m} / \mathrm{f}$ ratio 2.90 ) and in aortic valve stenosis ( $\mathrm{m} / \mathrm{f}$ ratio 2.83 ) corresponds with results of other studies $[11,12,17]$.

Prematurity as well as a low birth weight, which are partly associated, are more frequent among infants of all severity categories of CHD when compared to the national average. We further noted that patients with a univentricular heart or a transposition of the great arteries were more frequently born at term and with a normal birth weight than patients with other CHD, confirming previous observations [20].

The numbers of associated extracardiac organ malformations or genetic anomalies reported by us are lower than those mostly reported by others [16], which is probably due to the diagnosis assessment made very early within the first year of life.

We further report on a relatively high occurrence of multiple births in newborns with CHD which was particularly common in mild lesions as found before by Pradat et al. [17]. The reasons for high rates of multiples among CHD births remain unexp- lained as data on fertilization modalities or the proportion of monochorionic/diamniotic twins [2] were not available in our study.

Based on the parents' own reports of prenatal history, the detection rates for univentricular heart and other severe lesions by echocardiography were fairly high while the general detection rate of CHD was as low as reported by others [15].

CHD was diagnosed early after birth: more than one half of the patients were detected within the first month and more than $80 \%$ within three months of life. These numbers may be taken to reflect the qualified postnatal diagnostic care in Germany. As could be expected, the diagnosis was made earlier in infants with more severe cardiac defects.

It is a strength of the PAN study that it covers a large European country with a high level of completeness. To our knowledge this study enrolls the largest number of CHD within a one year period of data acquisition ever reported. Furthermore, the EPC-code was used for classifying cardiovascular lesions which offers advantages over the widely used international code of diseases (ICD) with its restricted differentiation of the single malformations. As a limitation, the proportion of anonymous reports - 
Table 3 Numbers and proportions of birth weight $<2500 \mathrm{~g}$, gestational age $<37$ weeks and multiple births among all live births in Germany and PAN patients born from July 2006 to June 2007.

\begin{tabular}{|c|c|c|c|c|}
\hline & Numbers & $\begin{array}{c}\text { Birth weight }<2500 \mathrm{~g} \\
(\%)\end{array}$ & $\begin{array}{c}\text { Gestational age }<37 \text { weeks } \\
(\%)\end{array}$ & $\begin{array}{c}\text { Multiple birth } \\
\text { (\%) }\end{array}$ \\
\hline Total live births per year in Germany* & 669298 & 6.8 & 9.1 & 3.3 \\
\hline PAN patients** & 5172 & 17.5 & 18.7 & 6.2 \\
\hline \multicolumn{5}{|l|}{ - Single CHD entities: } \\
\hline - VSD & 2598 & 14.0 & 15.2 & 5.2 \\
\hline- ASD $\|$ & 816 & 26.0 & 29.3 & 9.3 \\
\hline$-P S$ & 295 & 15.9 & 18.4 & 7.6 \\
\hline - PDA & 241 & 29.0 & 33.1 & 9.0 \\
\hline$-\mathrm{CoA}$ & 184 & 17.9 & 15.2 & 6.9 \\
\hline$-U V H$ & 138 & 10.9 & 12.8 & 4.4 \\
\hline- AVSD & 126 & 23.8 & 21.5 & 4.5 \\
\hline - TOF & 135 & 20.0 & 14.9 & 5.1 \\
\hline- AS & 120 & 17.5 & 19.8 & 5.6 \\
\hline - D-TGA & 123 & 6.5 & 8.9 & 3.2 \\
\hline - DORV & 56 & 21.4 & 20.4 & 7.1 \\
\hline - PA/VSD & 37 & 24.3 & 16.7 & 2.9 \\
\hline - TAPVC & 28 & 17.9 & 21.4 & 3.6 \\
\hline - TAC & 24 & 33.3 & 20.8 & 4.2 \\
\hline - Ebstein's anomaly & 22 & 22.7 & 27.3 & 4.5 \\
\hline
\end{tabular}

* Source: German Federal Statistical Office and the German National Institution for Quality Assessment with data on birth weight, gestational age and multiple pregnancy

** PAN registered patients with complete information on birth weight, gestational age and multiple pregnancy

For abbreviations see footnote of $\bullet$ Table 2

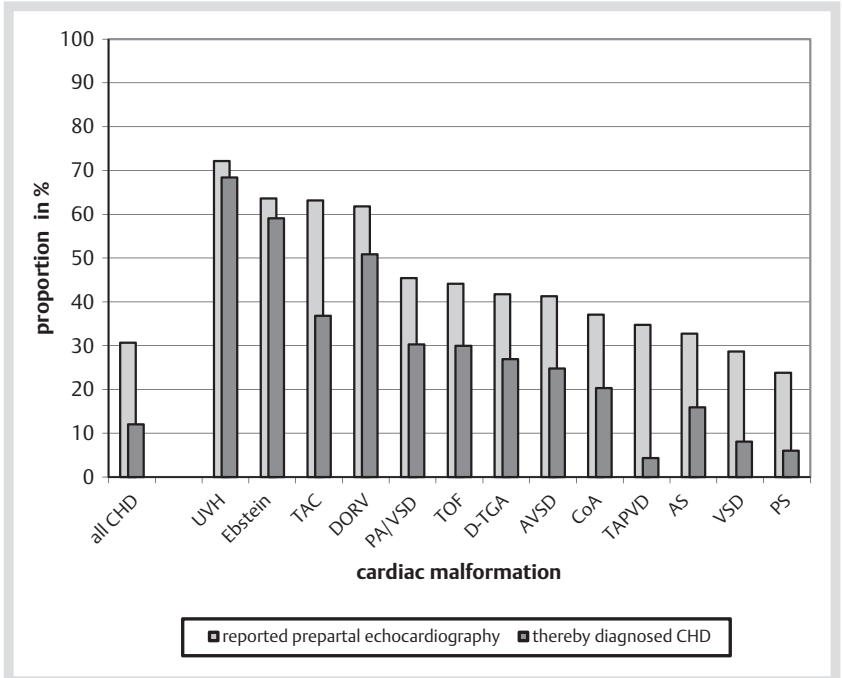

Fig. 1 Proportion of prenatal screening by echocardiography and of subsequent CHD diagnosis. Included are infants with complete data set and with information on prenatal screening given by the parents ( $\mathrm{n}=4$ 796). For abbreviations see footnote of $\square$ Table 2 .

though containing full medical diagnoses - limited some subgroup analyses, e.g. influence of birth weight and gestational age. However, since baseline characteristics were equally distributed between complete and anonymous cases, it is unlikely that selection bias has influenced these results.

\section{Conclusion}

The PAN study reports a prevalence of $1.08 \%$ of CHD among all live births in a German national register.

The high proportion of mild CHD indicates a good diagnostic coverage early in life. The prevalence of severe malformations is

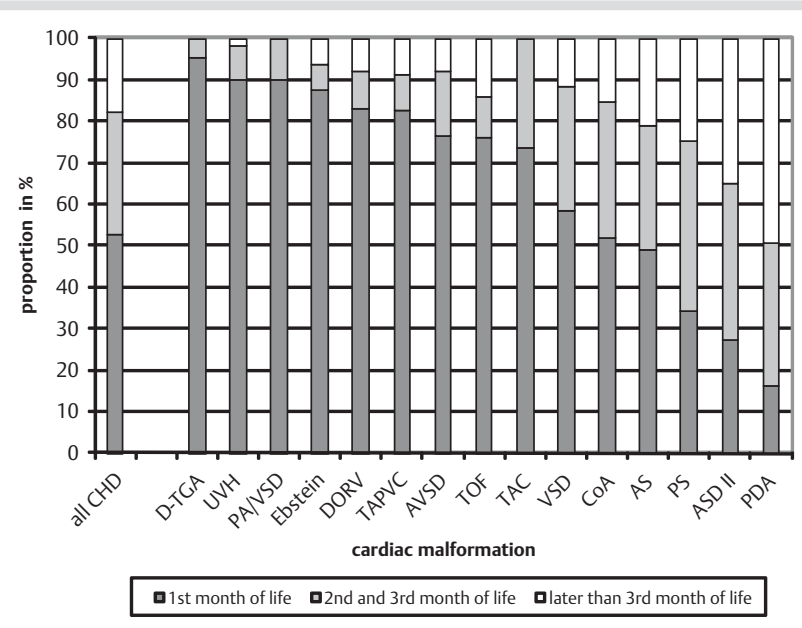

Fig. 2 Time of postpartal diagnostic assessment, by type of CHD. Included are infants with complete data set and information on time of diagnosis $(n=4494)$. For abbreviations see footnote of $\bullet$ Table 2 .

concordant with reports of others. CHD in live births is associated with a high proportion of prematurity, low birth weight and multiple births. The ongoing data acquisition of the PAN study will stabilize estimates of prevalence in particular for the rare cardiac lesions and will provide a basis for follow-up studies on etiological and prognostic factors.

This study is being supported by the Competence Network for Congenital Heart Defects funded by the Federal Ministry of Education and Research, [FKZ 01GI0601].

This publication is dedicated to P. E. Lange, the founder of the Competence Network for Congenital Heart Defects, for his constant encouragement and support of the study. 


\section{Acknowledgements}

$\nabla$

The authors are grateful to the following:

- All institutions participating in the PAN study. They are listed in the "Supporting Information".

- J. Frei, M. A. Körten, J. Olchvary and A. Meyer-Rapp for their assistance in data collection and management.

- The Network Central Office, Berlin, the CIO-Office, University of Göttingen and the Biostatistics Department, University of Magdeburg for providing infrastructural facilities and support.

We wish to thank G. Graham for his critical reading of the manuscript.

Conflict of interest: The authors have no conflict of interest to disclose.

\section{References}

1 Coding Committee of the Association for European Paediatric Cardiology. The European Paediatric Cardiac Code: the first revision. Cardiology in the Young 2002; 12: 1-211

2 Bahtiyar MO, Dulay AT, Weeks BP et al. Prevalence of congenital heart defects in monochorionic/diamniotic twin gestations: a systematic literature review. J Ultrasound Med 2007; 26: 1491-1498

3 Baspinar O, Karaaslan S, Oran B et al. Prevalence and distribution of children with congenital heart diseases in the central Anatolian region, Turkey. Turk J Pediatr 2006; 48: 237-243

4 Bosi G, Garani G, Scorrano M et al. Temporal variability in birth prevalence of congenital heart defects as recorded by a general birth defects registry. J Pediatr 2003; 142: 690-698

5 Botto LD, Lin AE, Riehle-Colarusso T et al. Seeking causes: Classifying and evaluating congenital heart defects in etiologic studies. Birth Defects Res A Clin Mol Teratol 2007; 79: 714-727

6 Capozzi G, Caputo S, Pizzuti R et al. Congenital heart disease in liveborn children: incidence, distribution, and yearly changes in the Campania Region. J Cardiovasc Med (Hagerstown) 2008; 9: 368-374
7 Dilber D, Malcic I. Spectrum of congenital heart defects in Croatia. Eur J Pediatr 2009, DOI 10.1007/s00431-00009-01064-00433

8 Germanakis I, Sifakis S. The impact of fetal echocardiography on the prevalence of liveborn congenital heart disease. Pediatr Cardiol 2006; 27: 465-472

9 Hoffman JI, Kaplan S. The incidence of congenital heart disease. J Am Coll Cardiol 2002; 39: 1890-1900

10 Kaemmerer $H$, Hess J. Adult patients with congenital heart abnormalities: present and future. Dtsch Med Wochenschr 2005; 130: 97-101

11 Kornosky JL, Salihu HM. Getting to the heart of the matter: epidemiology of cyanotic heart defects. Pediatr Cardiol 2008; 29: 484-497

12 Lisi A, Botto LD, Rittler $M$ et al. Sex and congenital malformations: an international perspective. Am J Med Genet A 2005; 134A: 49-57

13 Marelli AJ, Mackie AS, Ionescu-Ittu R et al. Congenital heart disease in the general population: changing prevalence and age distribution. Circulation 2007; 115: 163-172

14 Moons P, Sluysmans T, De Wolf D et al. Congenital heart disease in 111225 births in Belgium: birth prevalence, treatment and survival in the $21^{\text {st }}$ century. Acta Paediatr 2009; 98: 472-477

15 Nikkila A, Bjorkhem G, Kallen B. Prenatal diagnosis of congenital heart defects - a population based study. Acta Paediatr 2007; 96: 49-52

16 Oyen N, Poulsen G, Boyd HA et al. National time trends in congenital heart defects, Denmark, 1977-2005. Am Heart J 2009; 157: 467-473 e461

17 Pradat P, Francannet C, Harris JA et al. The epidemiology of cardiovascular defects, part I: a study based on data from three large registries of congenital malformations. Pediatr Cardiol 2003; 24: 195-221

18 Queisser-Luft A, Wiesel A, Stolz G et al. Klinisches Neugeborenenscreening zur Erfassung angeborener Fehlbildungen. Ergebnisse und Perspektiven des Geburtenregisters Mainzer Modell. Monatsschr Kinderheilkd 2001; 149: 1319-1325

19 Reng C-M, Debold P, Specker C et al. Generische Lösungen zum Datenschutz für die Forschungsnetze in der Medizin. Berlin: Medizinische Wissenschaftliche Verlagsgesellschaft; 2006

20 Tanner K, Sabrine N, Wren C. Cardiovascular malformations among preterm infants. Pediatrics 2005; 116: e833-e838

21 Wren C, Richmond S, Donaldson L. Temporal variability in birth prevalence of cardiovascular malformations. Heart 2000; 83: 414-419 